\title{
Vicarious futurity: Parents' perspectives on locating strengths in adolescents with autism
}

Jeanette L. Hastie ${ }^{1}$ and Christine Stephens ${ }^{2}$

\begin{abstract}
INTRODUCTION: Parents' perspectives of strengths in adolescents with autism is the focus of this research. Children with Autism Spectrum Disorder (ASD) have some of the best outcomes for cognition, communication and social development when they begin intensive treatment during early childhood. Most research in ASD has focussed on this part of the lifespan. This has tended to ignore the need for research that covers the whole lifespan including adolescence and adulthood, where extremely poor outcomes often emerge. Furthermore, from a reductionist biomedical view of $A S D$, research into adolescence and adulthood has highlighted the maladaptive and pathological behaviour of people with ASD.
\end{abstract}

METHODS: This qualitative study provides a space for parents to identify the strengths of adolescents, aged from 13-19 years, with ASD. Parents with the experience of raising an adolescent with ASD were asked to take or gather five photographs that displayed the strengths of the adolescent. Data were generated through the discussion of the photographs between the parent(s) or primary caregivers of the adolescent and the researcher. Eight families, with nine adolescents were recruited for the research and 10 parents were interviewed.

FINDINGS: The results of the research suggest that parents could identify strengths in adolescents with ASD and that these strengths were evaluated relative to diagnostic features of ASD or as supportive of daily family functioning. Furthermore, identifying adolescent strengths supported the parents' hopes for the future, described as "vicarious futurity."

CONCLUSION: This perspective poses a challenge to the common assumptions that ASD is associated with dysfunctional family life dominated by poor parental mental health, caregiver burden and research that objectifies those with ASD as being challenging. Identifying strengths points to more opportunities for success for an adolescent with ASD.

KEYWORDS: Autism Spectrum Disorder (ASD); adolescents; strengths; family functioning

The contribution of positive adjustment and optimism of families with adolescents with disabilities has been shown to decrease some ongoing stressors associated with parenting an adolescent with Autism Spectrum Disorder (ASD) (Snyder, Rand, \& Sigmon, 2002). There is little research to support this positive perspective. ASD is lifelong and $84 \%$ of adolescents with ASD reside with their caregivers well into adulthood, hence research to illuminate positive perspectives of ASD is needed. According to Benjak (2009), there is clear evidence in research highlighting an increase in negative experiences for parents of adolescents with ASD when compared
${ }^{1}$ Toi Ohomai Institute of Technology

${ }^{2}$ Massey University
AOTEAROA NEW ZEALAND SOCIAL WORK 31(1), 89-100.

CORRESPONDENCE TO: Jeanette L. Hastie jan.hastie@toiohomai.ac.nz 
with other clinical and non-clinical groups. There are many parental stressors in the experience of raising an adolescent with ASD, including a parent's mental health and well-being that, according to Duarte, Bordin, Yazigi, and Mooney (2005), correlate with the severity of the autistic behaviours exhibited by the adolescent. Other negative impacts for parents of adolescents with ASD include stigma, uncertainty about the future, corrosion of marital or child-parent relationships, feelings of loss and grief, and a lack of perceived social support and attachment (Falk, Norris, \& Quinn, 2014).

Adolescents with ASD often demonstrate special skills and talents alongside deficits in cognitive abilities and personality structures. According to Boyd, Conroy, Mancil, Nakao, and Alter (2007), these special skills and talents can influence the development of other positive attributes for the adolescent and offset the less valued aspects of ASD.

Furthermore, focussing on positive abilities and contributions increases child-parent relationship satisfaction and creates hope for the future, a concept known as vicarious futurity.

Vicarious futurity is identified by Nunn (1996) as the hope and despair that one person has for another's future and links to the concepts of mastery and selfdetermination. Vicarious futurity connects to a parent being able to hold onto the aspiration of hope for the adolescent. The parent is also supported by a sense of responsibility and efficacy that aligns powerfully with an understanding of the sensitive periods (developmental stages), and consequently a need to plan for these as the adolescent ages.

Kenneth Nunn (1996) identified five important domains that relate to positive outcomes in health. The first domain is associated with a positive appraisal of the future where a parent holds a belief that their adolescent will get what they want in life. The second domain relates to perceived worth where a parent believes that the adolescent will live a valued and productive life. Mastery and control are addressed in domain three where a parent believes that the adolescent will be able to cope with most issues that they will face in life. The fourth domain describes having a sense of drive and enthusiasm where a parent holds a positive perspective of the adolescent as they move through new phases and stages in life. The fifth relates to future interpersonal support where a parent can predict that others will see their loved one as a person who will have a valuable and productive life.

Parents of an adolescent with ASD are aware that one day their child will be without their support. Ordinarily, parents do not live longer than their children and if a child is to grow into an adult who still requires support, the parent will need to plan for a future they envisage for their child in their absence (Morgan, 2009). Vicarious futurity is the key proposition of this research and is linked to the work of Kenneth Nunn (1996). In the present study we ask two questions: What strengths do parents identify in their adolescent children with ASD? How do parents describe their hope for the future through the strengths of their adolescents with ASD?

\section{Method}

\section{Research design}

A qualitative design was underpinned by hermeneutic phenomenology (Heidegger, 1962) in which human experience is highlighted in relation to shared meanings about the world. Hermeneutic phenomenology has several major assumptions whereby human experience located in temporal and cultural expressions and linked to family practices, abilities, and communication is collectively recognised and can capture the evolving story between the parent and the adolescent. According to Taylor (1991), we are constantly immersed in this hermeneutic sphere that creates knowledge and the identification or clarification of meaning 
of this shared knowledge is linked to the involvement of an interpreter (researcher) and the interpreted (the participant) in a semantic, dialogical relationship. From this standpoint, the researcher and the participant can be considered as part of the hermeneutic sphere where experiences of the researcher and the participant will collide, be negotiated, and accepted into a space where meanings are shared and understood by each other.

\section{Ethics}

Ethics approval for these procedures was granted by the Massey University Human Ethics Committee Southern B, Application 16/47, New Zealand in January 2017.

\section{Participants}

Participants were recruited through the specialist education sector and nongovernmental organisations (NGOs) which support people with disabilities in Aotearoa New Zealand. The various organisations were approached with information about the research and a request to post out participant invitations and information sheets to parents and primary caregivers of adolescents between 13-19 years with a diagnosis of Autism. Four organisations agreed to participate and used their own data-bases to invite those who fit the criteria.
Eight families agreed to participate.

Although the parent was the primary participant, the adolescent was treated as a participant with their own agreements, acknowledging their right to know that the research was about them. An adolescent consent form was designed for those who could understand the meaning of giving consent to participate in the research (as assessed by their caregiver). An adapted social story form was developed for those adolescents whose parents felt that this was the best design to support their understanding. These forms were given to the parents at the initial interview and it was explained how the parents could support the adolescent to sign these forms.

Table 1 identifies the participants, the gender and age of the adolescent with ASD and any co-morbid diagnosis with ASD. The pseudonym was provided by the parent or the adolescent.

\section{Procedures}

The first author met with the participants in their homes to describe the research in full and to gain consent to participate in the research. The parents were informed of their rights and time was taken to answer any of their questions. The research required parents to present five photographs that the parents felt displayed the strengths of their child. At a second meeting, the first author

Table 1. Participants' Details

\begin{tabular}{|l|c|c|c|c|c|}
\hline $\begin{array}{c}\text { Parent } \\
\text { Participant }\end{array}$ & $\begin{array}{c}\text { Adolescent } \\
\text { Gender }\end{array}$ & $\begin{array}{c}\text { Adolescent } \\
\text { Age }\end{array}$ & $\begin{array}{c}\text { Adolescent } \\
\text { Co-morbidity (if any) }\end{array}$ & $\begin{array}{c}\text { Adolescent } \\
\text { Pseudonym }\end{array}$ & $\begin{array}{c}\text { Adolescent } \\
\text { Relationship (if any) }\end{array}$ \\
\hline Participant 1 & Female & 14 years & Alexandra \\
\hline Participant 2 & Male & 19 years & Intellectual Disability & Brandon \\
\hline Participant 3 & Male & 15 years & - & Finn \\
\hline Participant 4 & Male & 14 years & Intellectual Disability & Todd \\
\hline Participant 5 & Male & 14 years & General Anxiety Disorder & Tia \\
\hline Participant 6 & Female & 14 years & Visual impairment & - Miranda \\
\hline Participant 7 & Male & 19 years & - & Thins \\
\hline Participant 8 & Male & 14 years & Thomas \\
\hline
\end{tabular}


conducted semi-structured interviews in which the photographs were used to elicit data through the conversations guided by a set of general questions about strengths. Three adolescents were present during the interviews with their parent or primary caregiver and two of the adolescents made comments in response to some or all of the questions presented by the researcher and these comments were included in the data.

\section{Analysis}

The interviews were recorded using a digital voice recorder. After being transcribed and approved by the participants, these data were analysed using latent thematic analysis (Braun \& Clarke, 2006). Atlas.ti software (Friese, 2012) was used to identify repetitive words and patterns of talk used by the parents as they discussed the photographs. Common themes were identified and interpreted in terms of the strengths or special attributes that the adolescent displayed. These themes were compared across the participants to identify patterns of shared meaning associated with the strengths displayed by adolescents with ASD.

\section{Findings}

Strengths and special attributes identified by the parents included social skills, researching information on the internet, the use of advanced and simple technology, memory, cooking ability, artistic ability, bravery, perseverance, humour and autonomy. The identification of strengths and a positive perspective of the future were linked to the diagnostic features of ASD through the lens of the five domains of vicarious futurity.

The analysis identified three broad approaches taken by parents to identify the strengths of their children. The first approach related to overcoming the limitations experienced by adolescents with ASD. The diagnostic features of ASD are associated with three core areas of difficulty with socialisation, communication and cognition.
Any positive development in any one of these areas was identified by the parents as a strength. Secondly, parents recognised the strengths that were part of ASD. Many of these strengths, such as memory or the need for fixed or rigid routines were seen as special gifts that could enhance their child's life and the life of their family and associates. Thirdly, several parents recognised personal qualities and strengths in their children described as determination, perseverance and being happy that supported the parents to have a positive perspective of their child's future. These strengths together or individually were seen as valuable for the future of the adolescent.

\section{Overcoming the limitations}

\section{Socialisation}

Most of the adolescents in the research struggled with socialisation. This included a marked impairment in social and emotional reciprocity, development of peer relationships and verbal and non-verbal communication (American Psychiatric Association, 2013). The ability to socialise with others within and outside the family was highly valued by the parents. Some participant parents had focussed on helping their children develop these abilities. For example, Thomas's parents discussed this in terms of Applied Behaviour Analysis (ABA) that taught Thomas to communicate, and therefore socialise. Thomas and his family had engaged with ABA from when Thomas was young, and they saw the resulting socialisation skills as an important strength:

He has built quite a social network. That is not a trait that people with Autism usually have. We get the feeling that we were really lucky to kind of haul him out of the autistic place he was in, a bit more into the real world. All the ABA we did with him for years and years. We taught him to talk, taught him to read, we taught him everything through that. Positive side, we couldn't be happier really, what he has achieved and where he is going. 
He seems to have a lot of female friends. They like him and they kind of look after him. And he organizes them to take him out on a date, go for coffee or go to movies. Facebook has been a boon for Thomas. He can communicate from home here to his friends. All of his friends are on it. And all of his friends are female pretty much, all of them.

Socialisation included a strong cultural influence for Brandon who is Māori. Brandon has ASD and an intellectual disability and has not developed spoken language but does communicate with sounds and gestures. When meeting a niece for the first time, Brandon performed the haka (traditional Māori dance formalising unity). It cannot be understated how important this is in terms of using a ceremonial method where he identifies her as whānau and formalises this relationship through him performing the haka that identifies how he is connected with her. Whakawhanungatanga (reciprocal relationships) is underpinned through the formal announcement of who you are, where you are from and aligns with the values and belief of whānau (family) for Māori. Brandon's aunt, his primary caregiver, described this interaction in this way:

Yes, and so I noticed that whenever he needed to meet anyone, and I was telling him look someone's coming, you're going to have to meet so and so, and when they come, he'll greet them normally, but with her, it was the first time that I ever seen him have a little korero with her, then the haka with her, everyone else he will just have a little mihi to them, and then just sit down, but with her, he done the haka. And when she sees him on Facebook, and they talk, it's like they understand with each other, she is jabbering away in her baby talk and he goes " $\mathrm{mm}$ ", and she goes "Ok bye uncle Brandon", and he goes "Bye bye", and he turns the camera off.

Another way of recognising social abilities was by focussing on the adolescents' own particular strengths in socialising. Cooking and sharing food with others also supports connections of family and friends. Food is culturally located in celebrations and rituals and allows a space for others to compliment the person who did the cooking, building self-esteem and a sense of belonging. Alexandra's mother discussed Alexandra's talent for cooking, her artistic presentation of her baking, and contributions to family occasions. Although the impacts of ASD require Alexandra to have one-on-one support when cooking, her mother presented this talent as a strength that contributes to family life:

Cooking, she has an incredible ability to judge whether something is sweet enough, tart enough, doesn't always need to follow the recipe to a tee, she is very talented. Cooking, obviously everyone enjoys it, and food always brings family together, so when there is a birthday or a special occasion, Alexandra will always bake and what better way to bring family together as said other than food.

This recognition was in contrast to her mainstream school experiences. Alexandra herself discussed the positive reactions she received from her family's recognition of this strength which was contrasted with her experiences at mainstream school:

[O]h yeah baking, I bake it and my stepdad eats it all, if we don't get it in time, technically I make it for him, so yeah, they enjoy it and I take it to school [current alternative school] and they just love it and they say make more, I think they love it...I don't think my talents were recognised at school [mainstream], when I was there, which is pretty sad, so stuff you school. The people at school [mainstream] I feel sorry for because they don't get recognised.

Being able to socialise, develop and maintain friendships was a vital element for the parents to have a positive outlook for the future of their son or daughter. Another vital element for the parents linked to the 
adolescent being able to communicate through reciprocal discussions especially for those who had difficulty in talking or in other ways such as creating art. Some of the adolescents were artists and art became a way to talk, discuss and express their ideas about themselves.

\section{Communication}

A number of the parents in the research identified artistic talents as providing additional strengths for their children and it is suggested that art is a splinter skill that is associated with ASD (Treffert, 2009). Miranda's mother presented her daughter's drawings during the interviews and this became a talking point about Miranda's strength and talent in creating beautiful pieces of artwork. Miranda's mother additionally saw Miranda's talent as an opportunity for self-expression and self-determination. Miranda has a visual impairment and according to her mother, when drawing eyes in her artwork, they are large, intricate, and colourful because Miranda is challenging herself.

I have had friends that have come around and gone, that is amazing Miranda, could you draw a picture for me? I think that sometimes Miranda has a real focus or concentration on eyes because she identifies that as a deficit, so she wants to draw them as perfect as possible, but she is unbelievably talented.

Alexandra is also a talented photographer who has produced work that includes landscapes and macro shots of bees and flowers. This is a solo activity that takes time, persistence, and a keen eye for artistic composition which Alexandra brings to the work greatly admired by her mother.

Tia makes small, delicate and intricate clay figurines to relax and her mother talks about how this activity supports Tia during times when anxiety is overwhelming for her. It is an activity that she does alone, sitting quietly for hours making these figurines lowering her anxiety and providing space for her to think and to make safe decisions. This understanding is supported in research where creating art is a form of stress relief and therapy (Curl, 2008).

The achievement of socialisation and related communication skills was an important strength recognised by the parents in different ways. Cognitive functioning was also often seen as a strength in terms of special abilities manifested in the use of technology.

\section{Cognition}

Activities using technology are often solo activities that suit the diagnostic features of ASD, and provide opportunities for cognitive, communication and social development. The use of technology included both advanced skills like streaming live interactive games and simple technology like reading a book or an eBook on a tablet. Every adolescent in this study used the internet in some way and this activity was linked to the development of learning for most families. For example, Todd used the internet to research areas of interest and his father commented that his love for technology has supported his learning and developed his communication skills:

He does a lot of you-tubing, a lot of research, that he will find the information he needs on the computer, it's got to a stage a while ago that, perhaps a year ago, researching operations. You would wander out to his screen and there would be an operation going and people would be getting their gall bladders out or whatever he was particularly interested in at the time, all of his research, even a lot of the way he talks is all generated from what he has watched on the computer.

Finn is an example of an adolescent who has very advanced computer skills and is employed after school in a computer repair shop. He has been part of the Microsoft "Insiders Program" since its inception. This 
is an internal Microsoft community that tests software for Microsoft before it is released for sale to the public worldwide. Finn has been offered employment by Microsoft as described by his mother:

Computers, he is part of the windows insider program, he has been involved with that since it started. Yeah so, the woman who sent him the Surface Pro, has told him via email that she wants to employ him, so these people are genuinely impressed by his ability in terms of programming.

Finn took part in the semi-structured interviews and talked about how his skills fixing computers were valued by others.

Are you kidding me, even my teachers tend to come to me before they go to the IT guys just to see if I can fix it before they go to the techies that are so busy, and it always takes forever to get something fixed.

Reading is a solo activity and therefore works well for Tia who has ASD and General Anxiety Disorder. Reading eBooks on her tablet is, according to her mother, a way for Tia to understand her experiences of the world that is often overwhelming for her. By researching and reading about her experiences in a quiet space, Tia to starting to form her own identity.

Literacy is her thing. Her writing and her expression. Because she is so self-aware of how she feels, and she is aware of how much her anxiety affects her every day, joys of a high functioning autistic kid. Some of the stuff she is reading is beyond her years. It is because she questions everything, and she is not quite sure who she is, she is having a bit of an identity crisis at the moment with sexuality and all kinds of things.

Restricted interests are a common feature of ASD (Attwood, 2003) and many such interests were identified by a number of the parents as strengths for the adolescents. For example, Finn's restricted interest in all things regarding computers has facilitated an after-school job and raised his status among his peers and teachers. Being known as a computer programmer supports his self-esteem and friendships. Tia's restricted interest in selfhelp ideas, and her high reading ability has supported her understanding of her own anxiety and her ability to write expressively. Such success and new learning through the use of technology was considered a strength by every parent in the research.

\section{Strengths of ASD}

\section{Memory}

Having an excellent memory is a feature of ASD (Treffert, 2005) and Finn's mother talked about how Finn demonstrates a verbatim memory of what he reads. $\mathrm{He}$ remembers everyone's computer passwords, vehicle registration plate numbers of every vehicle ever owned by the family and other useful information.

He has the most incredible memory, I think he possibly has like a photographic memory, it's unbelievable, so when you ask him about some computing thing that is in his Window 7 bible, he will reel it off verbatim. It is just like the book.

Finn's recall of facts has allowed others to perceive him positively and supported his friendships. Interest in his abilities offsets his other more autistic traits such as interrupting other people's conversations constantly to talk about his own focussed interests.

Thomas's father discussed Thomas having an excellent memory that is linked to his high focus interest in local shops and stores in Tauranga. Thomas will go into a store and talk to the workers there about the history of the store often from when it was constructed. This provides an opportunity for Thomas to socialise within an environment he finds stimulating and often those store workers are responsive, polite and interested in what he has to say. 
The parents in this research recognised that skills around memory and recall that are often a positive feature of autism (Boucher \& Bowler, 2008) were linked to opportunities for successful socialisation and to developing new learning. These strengths were aligned with social norms of education and relationship building.

\section{Routines}

The predictability of routines supported daily functioning of the families across different environments including home, school and the community. Kanner (1946) highlights that those people with ASD are driven to seek sameness and many of the adolescents in this research enjoyed routines.

For Star Child's mother, the predictability of routines supported well-being for his family because his parents knew exactly what he was doing at the same time every morning.

He is our alarm clock [laughter]. 5.30am every morning. He puts the jug on, turns the TV on first, you hear the preaching go on, then he will pop on the jug. He will have three plates of 6 weetbix, 18 weetbix for breakfast. He is left handed, so you hear the click, you know exactly what action he is doing, he doesn't chew it or dissolve it, it is swallowed straight away. He will whistle up to the next lot, to do his next plate of 6 . He comes back down, you hear the bang crash, everything is so structured and robotic. It is beautiful. Everything right down to the amount of times he brushes his top teeth down to the bottom teeth, how many spits he does. Everything is just on cue. I love it. It is so predictable.

Other participants in the research described routines that were linked to a specific order of events or actions. These parents found such routines a strength for the adolescents in terms of the predictableness of daily life which facilitated family practices around home, school and work.

\section{Personal strengths}

Several of the parents also recognised individual strengths in personality displayed by their children that would help them to overcome any limitations imposed by their ASD. For example, Miranda's mother was very proud of her daughter's personal triumphs. Miranda belongs to a community organisation and has drawn on personal qualities of resilience and dogged persistence to be part of this group and its community activities. Her achievements were demonstrated by her being awarded a trophy for a "can-do attitude".

Star Child has ASD and a life-threatening health condition with a strong desire to take control over his life. This was exemplified by a photograph presented by his mother where Star Child, who had recently come out of six weeks in hospital including time in the intensive care unit, wanted his mother to take of him in the surf of the ocean. Star Child's mother discussed these series of photographs as Star Child "reclaiming freedom, belonging, and restoration of self". The photograph showed Star Child turning his back on a large wave crashing on the shore, showing his bravery and mastery of the elements, asserting his manhood, and making a pact that "he" is here for a reason. Star Child's mother believed that Star Child's smile in this photograph is "an invisible vibrational contract" formed spiritually between a loving mother and her son.

For Thomas's father, Thomas's personality is one of his greatest personal strengths and will support him in a future in which people want to be around him.

He is very intelligent, very smart person and he is a fun guy, he is happy, he has a lot of happiness in him, he has no malice, no problems at all. No kind of negative, no negative personality traits, or any of those sort of bad things, he has none of them. [They] all help him to get by in life and they will help him to be liked by people. And to fit into society better 
I guess. Which is always a wish for a parent. He is fun to have around. That is the good thing about his qualities. He has lots of good strengths that will help him get through life.

\section{Themes of Vicarious Futurity (hope for the future)}

Having hope for the future for these parents was associated with the understanding that adolescent strength and attributes could be utilised in the future, giving parents a hopeful perspective on the adolescent's life. These hopes may be considered in terms of Nunn's (1996) five domains of vicarious futurity.

Domain one relates to a positive appraisal of the future that links to a parent's belief that the adolescent will get what they want in life. This perspective was moderated by the differing cognitive or physical abilities of the adolescents and mediated through the understanding that the adolescent will likely require support throughout their lifetime. Parents who saw their children as having strengths across more than one of the three aspects: 1) overcoming the difficulties of ASD; 2) special talents associated with ASD; and 3) strong personal qualities, were most likely to talk about their children getting what they want in life. For example, Thomas's will-power and determination, coupled with his social skills meant he was able to get his needs met. Being able to communicate your needs is a large part of "getting by" and Thomas's father strongly believed that this strength would serve Thomas well in the future.

Because of the force of his will, he singlemindedly is focused on what he wants, and when you are like that people sort of just, not bow to your will, but they will say come over here and I will show you where that is, people will help you. Because you are determined to go where you are going, people will assist you normally.

Those parents who saw their children as having strong personalities also believed in this would positively influence the future for the adolescents: Miranda's mother believes that Miranda will get what she wants in life despite ASD and her visual impairment due to Miranda's motivation to achieve her goals. She said:

Yes, I think if she really wants something, she will get it, come hell or high water. I don't know if that is the Autism or just a born trait. The Autism makes it very cut and dried. She will set her mind to something and she will achieve it. At one point she said to me, "I'm going to find a cure for what is wrong with my eyes, and everything will be better." I was like, well you never know. I try to get her to see the beauty in her uniqueness.

Domain two recognises perceived worth and the parent's belief that their children will live a valued and productive life. Several parents believed that their children's talents and skills would serve them well in the future. For example, Finn's talent in computing will assure him of a career. Alexandra wants to be a photographer, and because of her artistic talents and photographic skills, her mother is very positive about this career choice. Professional photography is a respected profession that is associated with study and employment opportunities. Perceptions of a valued and productive life were often linked to the promise of prospective employment. Some participants recognised that a valued and productive life would be achieved by being a valued member of the family, participating in cultural activities, or the prospect of having relationships and a family of their own in the future.

Domain three relates to mastery and control and is associated with the parent's belief that their child will be able to cope with most issues and concerns that they will face across their lifetime. Tia's mother believed that Tia will be able to cope with most issues in her life because of her good problemsolving skills that are supported by being an avid reader and finding information and inspiration through knowledge. 
Domain four relates to drive and enthusiasm that links to the parents maintaining a positive perspective of the adolescent as they move through new stages and phases in life. Finn's mother was confident that the parenting investment made by both parents would be the crucial element for Finn getting through life.

[T] here will be some things that which will be quite difficult, but hopefully we would have done a good enough job that he will be able to manage most things.

Domain five of vicarious futurity highlights future interpersonal support where the parent believes other people will recognise and acknowledge the attributes and strengths that the adolescent demonstrates will support them to have a valued and productive life. Some parents, such as Star Child's or Brandon's, saw that family support would be the vital element in the future. Other parents, such as those of Thomas and Finn saw their personal qualities and learned skills as enabling wider social support.

Several parents expressed both hopes and fears for their children's futures. Often these were expressed in terms of the contribution that the adolescents' strengths would make to the community, and fears that these strengths are not sufficiently recognised by society. Finn's mother discussed this in terms of others recognising strengths over the less valued behaviours of ASD.

Yeah and I see so many strengths and incredible abilities that are not valued because of the other side of ASD. I just think we are missing out on a huge incredibly valuable resource that is right there, I think it will be maintained by other people acknowledging his strengths and ignoring his quirks.

Parents were concerned about their children's future that will see others caring or making decisions for them and this is exemplified by Tia and Todd's mother:
I want people around both of them that are going to care. And right now, they have their immediate family, but most of their immediate family is older than us. Do you know what I mean? Because Tia is higher functioning I do not want Todd to become her problem. I want Todd to be her brother. The twins' dad and I often say maybe we should have had another one, if our family had been bigger there would be more support around him. But then on the other hand, I know big families with special needs kids and no one wants anything to do with the special needs child because they are just too hard.

I would like to see Tia living independently. Being happy, to be able to do what she wants to do. Achieving the things, she wants to achieve. And being safe. All I want is people around the kids that have their best interests at heart and it's not all about the money, having the community around them, but it is just finding it though.

\section{Discussion}

These parental hopes highlight the need for broader support from society. According to Eaves and Ho (2008) there is little research on the unmet needs that would inform community support for adolescents with ASD as they enter adulthood. Entering the adult disability system in Aotearoa links to residential services, supported living services and benefits from Work and Income. Recently there has been a rise in the number of individually funded services that can develop a wraparound service for adolescents with ASD provided they reach a specific assessed level of need (Ministry of Health, 2016). The parents' hopes for their children were focussed on the need for a broader social recognition of the contributions they would be able to make as adults. Focussing on their children's strengths enables the parents to recognise the potential for a positive future and broader recognition of the contributions of people with ASD. 
The special skills and talents of the adolescents identified by the parents were filtered through some of the diagnostic features of ASD that are useful in everyday family life. Any positive developments in the three areas of deficit, socialisation, communication and cognition were highly valued because they were functionally beneficial for the adolescent in different environments including home, school and other mainstream settings. Parents fostered many of the positive features of ASD to offset the less valued behaviours of ASD. These included the adolescent preferring routines, natural talents, knowledge of technology, an excellent memory, and recall of facts and figures. These strengths supported the adolescent to get to school on time, research on the computer often increased their language and knowledge in areas of interest, and having an excellent memory facilitated success in school and other areas of life.

Being able to socialise, communicate and problem-solve were identified as strengths by the parents who perceived these skills as being valuable in the future. Social skills were clearly linked to friendships and interpersonal relationships that would be supportive as the adolescent ages. Being social is associated with being able to communicate effectively and parents felt that if the adolescent could communicate appropriately, this increased the chances of them getting what they want in life by simply being able to ask for it. This was supported by an understanding that societal expectations for reciprocity of communication is vital for acceptance from others.

Parents in the research highlighted fostering the valued attributes of ASD like memory, routines, and artistic ability as a mechanism for the adolescent to experience success as often as possible now and in the future. Furthermore, by paying attention to these valued attributes, they were naturally increased. Some of the identified adolescent strengths were associated with gaining some sort of employment, building relationships or linked to a meaningful way to spend their day including their talents in photography, art, computer programming and computer use. Special skills like cooking were highlighted by the family as a valued part of celebrations and art was valued as part of adorning and decorating family homes. Furthermore, many of the identified strengths supported the adolescents to engage in favoured activities and allowed spaces for respite for the parents or time to complete ordinary household tasks like preparing family dinners and supporting other members of the household.

Identification of vicarious futurity by the parents was closely linked to level of functioning of the adolescent across the diagnostic features of ASD. Therefore, those parents whose adolescents were social, could communicate effectively and were cognitively capable, held a strong positive perspective of the future. Parents of those adolescents with lower level of skills adjusted their expectations for the future, however, they remained positive about what the future might hold for the adolescent through the strengths and skills they demonstrated. Being able to hold this positive perspective has been highlighted in the literature as a protective factor for the health and well-being of parents raising an adolescent with ASD (Neely-Barnes, Hall, Roberts, \& Graff, 2011). Moreover, parents in this research worked on the strengths that their children currently displayed and continued to work in other areas of valued behaviours such as sportsmanship, anxiety management and extending communication and social skills.

\section{Conclusion}

Parents in this research embraced the paradox of raising an adolescent with ASD by supporting the diagnostic features of ASD to facilitate daily family life, provide opportunities for the adolescent to learn to talk, socialise, make and keep friends, 
participate in community activities and create their own unique identity. Pondering the future positively for parents was associated with the belief that the adolescent would experience a valued and productive life that will be acknowledged by others and that the adolescent could develop skills to manage most issues they are likely to face across their lifetime. Being able to hold this positive perspective is linked in this research to increased protective factors for health and well-being for parents, building resilience for them, and developing skills for the adolescent to be autonomous and more independent over time.

Focusing on normalising an adolescent with ASD has been the preferred intervention method to support an adolescent to fit into society. This approach ignores the inherent strengths that the diagnostic features of ASD offers and the expertise that parents offer in terms of accepting and utilising the "quirks" of ASD to support positive outcomes for the adolescent and their family. By ignoring these strengths, we are missing a large pool of tangible interventions that may provide family satisfaction, more positive child-parent relationships and more opportunities for success for an adolescent with ASD.

\section{Acknowledgements}

Funding for this research was provided by Massey University, Palmerston North, New Zealand.

\section{References}

American Psychiatric Association. (2013). Diagnostic and statistical manual of mental disorders (5th ed.). Arlington, VA: American Psychiatric Publishing.

Attwood, T. (2003). Understanding and managing circumscribed interests. In M. Prior (Ed.), Learning and behavior problems in Asperger Syndrome (pp. 126-147). New York, NY: Guilford.

Benjak, T. (2009). Comparative study on self-perceived health of parents of children with autism spectrum disorders and parents of non-disabled children in Croatia. Croatian Medical Journal, 50, 403-409.
Boucher, J., \& Bowler, D. M. (Eds.). (2008). Memory in autism. Cambridge, England: Cambridge University Press.

Boyd, B. A., Conroy, M. A., Mancil, G. R., Nakao, T., \& Alter, P. J. (2007). Effects of circumscribed interests on the social behaviors of children with autism spectrum disorders. Journal of Autism and Developmental Disorders, 37, 1550-1561.

Braun, V., Clarke, V. (2006). Using thematic analysis in psychology. Qualitative Research in Psychology, 3(2), 77-101.

Curl, K. (2008). Assessing stress reduction as a function of artistic creation and cognitive focus. Art Therapy, 25(4), 164-169.

Duarte, C. S., Bordin, I. A., Yazigi, L., \& Mooney, J. (2005). Factors associated with stress in mothers of children with autism. Autism, 9(4), 416-427.

Eaves, L. C., \& Ho, H. H. (2008). Young adult outcome of autism spectrum disorders. Journal of Autism and Developmental Disorders, 38(4), 739-747.

Falk, N., H., Norris, K., \& Quinn, M. G. (2014). The factors predicting stress, anxiety and depression in parents of children with autism. Journal of Autism and Developmental Disorders, 44(2), 3185-3203.

Friese, S. (2012). Qualitative data analysis with ATLAS.ti. London, UK: Sage.

Heidegger, M. (1962). Being and time (J. Macquerrie \& E. Robinson, Trans.). New York, NY: Harper \& Row.

Kanner, L. (1946). Irrelevant and metaphorical language in early infantile autism. American Journal of Psychiatry, 103(2), 242-246.

Ministry of Health. (2016). Autism spectrum disorder. Retrieved from http://www.health.govt.nz/your-health/ conditions-and-treatments/disabilities/autism-service.

Morgan, P. L. (2009). Parenting an adult with disabilities or special needs: Everything you need to know to plan for and protect your child's future. New York, NY: AMACOM.

Neely-Barnes, S. L., Hall, H. R., Roberts, R. J., \& Graff, J. C. (2011). Parenting a child with an autism spectrum disorder: Public perceptions and parental conceptualizations. Journal of Family Social Work, 14(3), 208-225.

Nunn, K. P. (1996). Personal hopefulness: A conceptual review of the relevance of the perceived future to psychiatry. British Journal of Medical Psychology, 69(3), 227-245.

Snyder, C. R., Rand, K. L., \& Sigmon, D. R. (2002). Hope theory: A member of the positive psychology family. In C. R. Snyder \& S. J. Lopez (Eds.), Handbook of positive psychology (pp. 257-276). New York, NY, US: Oxford University Press.

Taylor, C. (1991). The interpretive turn: Philosophy, science, culture. New York, NY: Cornell University Press.

Treffert, D. A. (2005). The savant syndrome in autistic disorder. In M. F. Casanova (Ed.), Recent developments in autism research (pp. 27-55). New York, NY: Nova Science Publishers.

Treffert, D. A. (2009). The savant syndrome: An extraordinary condition. A synopsis: Past, present and future. Philosophical Transactions of the Royal Society, 364(1522), 1351-1357. 